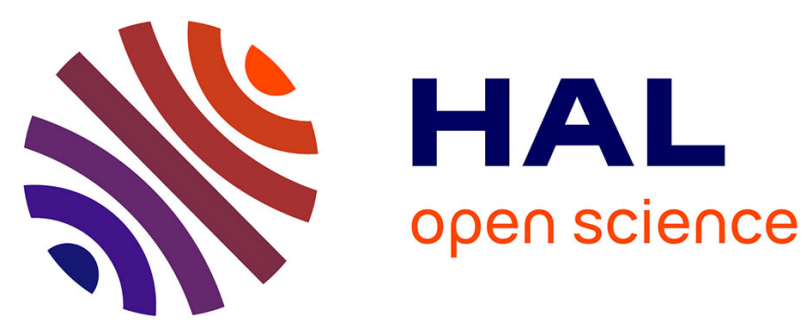

\title{
Assessment of the single-mixture gas assumption for the correlated K-distribution fictitious gas method in H2O-CO2-CO mixture at high temperature
}

\author{
Cyril Caliot, G. Flamant, Mouna El-Hafi, Yannick Le Maoult
}

\section{To cite this version:}

Cyril Caliot, G. Flamant, Mouna El-Hafi, Yannick Le Maoult. Assessment of the single-mixture gas assumption for the correlated K-distribution fictitious gas method in $\mathrm{H} 2 \mathrm{O}-\mathrm{CO} 2-\mathrm{CO}$ mixture at high temperature. Journal of Heat Transfer, 2008, 130 (10), 10.1115/1.2946475 . hal-01712153

\section{HAL Id: hal-01712153 \\ https://hal.science/hal-01712153}

Submitted on 8 Nov 2019

HAL is a multi-disciplinary open access archive for the deposit and dissemination of scientific research documents, whether they are published or not. The documents may come from teaching and research institutions in France or abroad, or from public or private research centers.
L'archive ouverte pluridisciplinaire HAL, est destinée au dépôt et à la diffusion de documents scientifiques de niveau recherche, publiés ou non, émanant des établissements d'enseignement et de recherche français ou étrangers, des laboratoires publics ou privés. 


\section{Assessment of the Single-Mixture Gas Assumption for the Correlated $K$-Distribution Fictitious Gas Method in $\mathrm{H}_{2} \mathrm{O}-\mathrm{CO}_{2}-\mathrm{CO}$ Mixture at High Temperature}

\author{
C. Caliot \\ e-mail: cyril.caliot@promes.cnrs.fr
}

\section{G. Flamant}

Processes, Materials and Solar Energy, PROMES CNRS,

66120 Odeillo-Font-Romeu, France

\section{El Hafi}

Centre de Recherche d'Albi en génie des Procédés des Solides Divisés,

De l'Energie et de l'Environnement,

Ecole des Mines d'Albi Carmaux,

81000 Albi, France

\section{Y. Le Maoult}

Centre de Recherche Outillages, Matériaux et Procédés, Ecole des Mines d'Albi Carmaux,

81000 Albi, France

This paper deals with the comparison of spectral narrow band models based on the correlated- $K(C K)$ approach in the specific area of remote sensing of plume signatures. The CK models chosen may or may not include the fictitious gas $(F G)$ idea and the single-mixture-gas assumption (SMG). The accuracy of the $C K$ and the CK-SMG as well as the CKFG and CKFG-SMG models are compared, and the influence of the SMG assumption is inferred. The errors induced by each model are compared in a sensitivity study involving the plume thickness and the atmospheric path length as parameters. This study is conducted in two remotesensing situations with different absolute pressures at sea level $\left(10^{5} \mathrm{~Pa}\right)$ and at high altitude $\left(16.6 \mathrm{~km}, 10^{4} \mathrm{~Pa}\right)$. The comparisons are done on the basis of the error obtained for the integrated intensity while leaving a line of sight that is computed in three common spectral bands: $2000-2500 \mathrm{~cm}^{-1}, 3450-3850 \mathrm{~cm}^{-1}$, and $3850-4150 \mathrm{~cm}^{-1}$. In most situations, the SMG assumption induces negligible differences. Furthermore, compared to the $C K F G$ model, the CKFG-SMG model results in a reduction of the computational time by a factor of 2 .

Keywords: radiative heat transfer, high temperature plume signature, remote sensing, spectral narrow band models, parametric study

\section{Introduction}

Modeling of plume signatures involves two main issues. On the one hand, the radiative properties of the combustion gases at high temperatures are necessary to compute the radiative heat transfer. This is an active research area (Refs. [1-4] and references therein). On the other hand, fast and accurate methods are required to describe the radiative heat transfer inside the plume and through the atmosphere. This paper addresses this issue. This study deals with the comparison of spectral narrow band models, based on the correlated- $K(\mathrm{CK})$ approach $[5,6]$ in the specific area of remote sensing of plume signatures. The evaluation of the accuracy of each narrow band model is done with the use of lineby-line (LBL) reference calculations.

In the long range sensing of plume signature, high temperature combustion gases, such as $\mathrm{CO}_{2}, \mathrm{H}_{2} \mathrm{O}$, and $\mathrm{CO}$, are also present in the atmosphere. In this type of application, emission is mainly due to the plume at high temperature, whereas absorption occurs principally in the atmosphere between the plume and a sensor. Contrary to the LBL model, the spectral interval of narrow band models includes many lines. Each of these line intensities depends on temperature. As the line location inside a narrow band is blurred, the CK approach can lead to a large overestimate of the atmospheric absorption.

To avoid this source of discrepancy, several models, including the fictitious gas (FG) idea, were developed [5,7-9]. The present authors [10] have proposed to extend the single-mixture-gas assumption (SMG) of Fu and Liou [11] used in meteorological applications to the remote sensing of plume signature in order to increase the computational efficiency of the CKFG model. The CKFG-SMG model considers the $\mathrm{H}_{2} \mathrm{O}-\mathrm{CO}_{2}-\mathrm{CO}$ mixture as a single complex gas, which is divided into FGs. As Fu and Liou [11] pointed out, the SMG assumption induces additional blurring in the narrow band because the radiation emitted by the lines belonging to one real gas can be absorbed by the lines of another gas. The SMG assumption leads to an overcorrelation of lines belonging to different real gases. This source of error has been studied in Refs. [10,12] with academic cases. In Ref. [10], the CK-SMG and CKFG-SMG models were presented and compared to a LBL reference calculation in academic configurations at the sea level pressure. As expected, the CKFG-SMG method achieved better accuracy than the CK-SMG method, especially when long atmospheric path lengths were involved. Moreover, in the test cases of Ref. [10], the SMG assumption resulted in negligible errors.

In this paper, we propose to compare the computational time and accuracy of narrow band models. These comparisons are conducted in two remote-sensing situations in which the altitude and the absolute pressure are different. The results of the CK, CKFG, CK-SMG, and CKFG-SMG models are compared to a LBL reference calculation. Furthermore, the validity of the SMG assumption is investigated for ground level and high altitude remotesensing applications.

\section{Description of the Radiative Transfer Method and the Spectral Models}

To compute the plume signature with the different spectral models cited previously, the radiative transfer equation has to be solved in a typical remote-sensing application. To evaluate the accuracy of spectral models, the medium is considered to contain only gases; scattering is not taken into account. The ray tracing method is well suited to compute the infrared intensity leaving a line of sight.

First, the ray tracing method is presented. Then, the CK and the CKFG models are presented, and special features of the CK-SMG and the CKFG-SMG models are given. The LBL approach is not detailed here because it is exposed and validated in Ref. [10].

Ray Tracing Model. The ray tracing method allows one to compute the intensity leaving a line of sight $[5,8,10]$. In the case of plume signatures, such a line of sight goes through a nonhomogeneous and nonisothermal medium containing a $\mathrm{H}_{2} \mathrm{O}-\mathrm{CO}_{2}-\mathrm{CO}$ mixture. Taking into account successive emis- 
sions and absorptions occurring along a line of sight passing through $N_{c}$ homogeneous and isothermal layers, the monochromatic intensity, $I_{\nu}$, leaving a line, is written as follows:

$$
I_{\nu}=\sum_{n=1}^{N_{c}} I_{b \nu}\left(T_{n}\right)\left[\tau_{\nu}\left(n, N_{c}\right)-\tau_{\nu}\left(n-1, N_{c}\right)\right]
$$

where $I_{b \nu}\left(T_{n}\right)$ is the monochromatic blackbody intensity at the temperature $T_{n}$ of the layer $n$, and the transmittivity $\tau_{\nu}\left(n, N_{c}\right)$ is the monochromatic transmittivity of layers from $n$ to $N_{c}$, that is defined by the following equation:

$$
\tau_{\nu}\left(n, N_{c}\right)=\prod_{n^{\prime}=n}^{N_{c}} \tau_{\nu n^{\prime}}=\exp \left(-\sum_{n^{\prime}=n}^{N_{c}} \kappa_{\nu n^{\prime}} \ell_{n^{\prime}}\right)
$$

with $\kappa_{\nu n^{\prime}}$ the monochromatic absorption coefficient of the gas mixture in the layer $n^{\prime}$ having a thickness $\ell_{n^{\prime}}$. The LBL method solves Eq. (1) to find the monochromatic intensity $I_{\nu}$ and requires monochromatic radiative properties, such as the monochromatic absorption coefficient of each gas present in the layer. In order to compare the intensities computed with the LBL approach and the narrow band models, the intensity spectrum obtained with the LBL (Eq. (1)) is averaged over a narrow band. Concerning the narrow band models, average radiative properties over a narrow band are used to compute the average intensity, $\bar{I}$, leaving the line of sight. For each narrow band, the expression for this intensity is written, as in Ref. [5].

$$
\bar{I}=\sum_{n=1}^{N_{c}} \overline{I_{b}}\left(T_{n}\right)\left[\bar{\tau}\left(n, N_{c}\right)-\bar{\tau}\left(n-1, N_{c}\right)\right]
$$

The transmittivity $\bar{\tau}\left(n, N_{c}\right)$ is a mean value in a narrow band of the transmittivity of layers from $n$ to $N_{c}$. The computation of $\bar{\tau}\left(n, N_{c}\right)$ is detailed in the following sections for each model. The main steps shared by all approaches are summarized below:

$$
\begin{gathered}
\tau_{i j}\left(n, N_{c}\right)=\exp \left[-\sum_{n^{\prime}=n}^{N_{c}} k_{j}\left(g_{i}\right) \ell_{n^{\prime}}\right] \\
\overline{\tau_{j}}\left(n, N_{c}\right)=\sum_{i=1}^{N_{q}} \omega_{i} \tau_{i j}\left(n, N_{c}\right) \\
\bar{\tau}\left(n, N_{c}\right)=\prod_{j=1}^{N} \overline{\tau_{j}}\left(n, N_{c}\right)
\end{gathered}
$$

where $k_{j}\left(g_{i}\right)$ is the $K$-distribution parameter for the gas $j$ at the quadrature abscissa $g_{i}$, which corresponds to the quadrature weight $\omega_{i} . N_{q}$ and $N$, are, respectively, the total number of quadrature points and the total number of gases. The $K$-distribution parameters $\left(k_{j}\left(g_{i}\right)\right)$ of each real gas $(\mathrm{CK})$ or fictitious gas $(\mathrm{CKFG})$ are computed from their line spectra. The $k_{j}\left(g_{i}\right)$ are then determined from the LBL spectra using a bisection method. They are obtained for a ten-point Gauss-Legendre quadrature and the width of a narrow band is fixed to $\Delta \nu=25 \mathrm{~cm}^{-1}$.

Correlated $\boldsymbol{K}$ Model and Correlated $\boldsymbol{K}$ Model With Fictitious Gases. The CK model considers each real gas of the mixture. The CKFG method consists of dividing one real gas into $N_{\mathrm{FG}}$ FGs, which include lines from the same interval of lower-state energy of transition, $\Delta E^{\prime \prime}$. Furthermore, in the CKFG approach, each real gas is divided into three FGs $\left(N_{\mathrm{FG}}=3\right)$. FGs of $\mathrm{H}_{2} \mathrm{O}$ and $\mathrm{CO}_{2}$ consist of lines with their $E^{\prime \prime}$ in the intervals $\Delta E^{\prime \prime}$, $0-2000 \mathrm{~cm}^{-1}, 2000-3000 \mathrm{~cm}^{-1}$, and $3000 \mathrm{~cm}^{-1}-\infty$. For CO, the three FGs classes are $0-900 \mathrm{~cm}^{-1}, \quad 900-3000 \mathrm{~cm}^{-1}$, and $3000 \mathrm{~cm}^{-1}-\infty$. Considering Eqs. (4)-(6) for the CK model, the subscript $j$ represents the three real gases of the gas mixture and

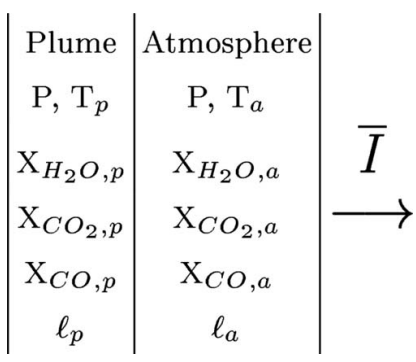

Fig. 1 Schematic description of the intensity leaving a line of sight, which goes through two layers, the high temperature plume and the atmosphere, both constituted of $\mathrm{H}_{2} \mathrm{O}-\mathrm{CO}_{2}-\mathrm{CO}$ mixture at the same pressure but with different temperatures and layer thicknesses

$N=N_{g}=3$. With the CKFG model, the subscript $j$ represents the FGs used for the gas mixture. If the mixture contains three real gases, then the total number of FGs is $N=N_{g} \times N_{\mathrm{FG}}=9$.

Correlated $K$ Model and Correlated $K$ Model With Fictitious Gases and the Single-Mixture Gas Assumption. The idea of $\mathrm{Fu}$ and Liou [11], who computed $K$-distribution parameters for a CK-SMG model, is extended to decrease the total number of FGs involved with the CKFG model and, consequently, enhance computational efficiency. The lines of $\mathrm{H}_{2} \mathrm{O}, \mathrm{CO}_{2}$, and $\mathrm{CO}$ gases are grouped to create three $\left(N_{\mathrm{GF}}=3\right)$ FGs of the mixture. The first FG is constituted of the lines from $\mathrm{H}_{2} \mathrm{O}$ and $\mathrm{CO}_{2}$ gases belonging to the $\Delta E^{\prime \prime}$ class, $0-2000 \mathrm{~cm}^{-1}$ and from $\mathrm{CO}$ gas with lines having their $E^{\prime \prime}$ in the $0-900 \mathrm{~cm}^{-1}$ range. The second and third FGs of the mixture are obtained similarly with the $\Delta E^{\prime \prime}$ classes cited previously. The CKFG-SMG model is used to compute Eqs. (4)-(6). In these equations, the subscript $j$ stands for a FG from the mixture where the total number of FGs is $N=N_{\mathrm{GF}}=3$. For the CK-SMG model, the subscript $j$ represents only the mixture, $N$ $=1$.

In the following section, a specific situation of remote-sensing application is described.

\section{Description of the Remote-Sensing Configurations}

The applications of remote sensing considered in this paper are assumed to take place in a subarctic summer atmosphere. The remote sensing of plume signatures is conducted at two altitudes where the absolute pressure and the atmospheric concentration of $\mathrm{H}_{2} \mathrm{O}$ are different. The line of sight is composed of two layers (see Fig. 1), the high temperature plume and the atmosphere with respective thicknesses, $\ell_{p}$ and $\ell_{a}$. The atmosphere for both altitudes is summarized in Table 1. The molar fractions of $\mathrm{CO}_{2}$ and $\mathrm{CO}$ are identical at both altitudes, and the temperature, pressure, and $\mathrm{H}_{2} \mathrm{O}$ molar fraction are obtained from the standard model of the subarctic summer [13]. Moreover, the high temperature value of the gaseous plume is $T_{p}=2000 \mathrm{~K}$, and the concentrations of the combustion gases inside the plume are representative of typical combustion products; the molar fractions are then, $X_{\mathrm{H}_{2} \mathrm{O}, p}=0.2$, $X_{\mathrm{CO}_{2}, p}=0.1$, and $X_{\mathrm{CO}, p}=0.05$. Also, the plume pressure is assumed to be the atmospherical pressure (depending on the cases in Table

Table 1 Description of the atmosphere composition in two remote-sensing cases with different altitudes

\begin{tabular}{lcccccc}
\hline \hline \multirow{2}{*}{$\begin{array}{c}\text { Case } \\
\text { No. }\end{array}$} & $\begin{array}{c}\text { Altitude } \\
(\mathrm{km})\end{array}$ & $\begin{array}{c}\text { Pressure } \\
P(\mathrm{~Pa})\end{array}$ & $\begin{array}{c}\text { Temperature } \\
T_{a}(\mathrm{~K})\end{array}$ & $X_{\mathrm{H}_{2} \mathrm{O}, a}$ & $X_{\mathrm{CO}_{2}, a}$ & $X_{\mathrm{CO}, a}$ \\
\hline Case 1 & 0 & $10^{5}$ & 287 & 0.012 & $370 \times 10^{-6}$ & $2 \times 10^{-5}$ \\
Case 2 & 16.6 & $10^{4}$ & 225 & $7 \times 10^{-6}$ & $370 \times 10^{-6}$ & $2 \times 10^{-5}$ \\
\hline \hline
\end{tabular}


Table 2 Number of $\tau_{i j}$ needed for each spectral model in different spectral intervals

\begin{tabular}{cccccc}
\hline \hline \multirow{2}{*}{$\begin{array}{c}\text { Spectral intervals } \\
\left(\mathrm{cm}^{-1}\right)\end{array}$} & LBL & CK & CKFG & CK-SMG & CKFG-SMG \\
\cline { 2 - 6 } & $10^{6}$ & 530 & 1590 & 210 & 630 \\
$2000-2500$ & $8 \times 10^{5}$ & 340 & 1020 & 170 & 510 \\
$3450-3850$ & $6 \times 10^{5}$ & 240 & 720 & 120 & 360 \\
$3850-4150$ & & &
\end{tabular}

Table 3 Spectral intervals where the gases $\mathrm{H}_{2} \mathrm{O}, \mathrm{CO}_{2}$, and $\mathrm{CO}$ overlap $\left(\Delta \nu=25 \mathrm{~cm}^{-1}\right)$

\begin{tabular}{ccc}
\hline \hline Spectral intervals $\left(\mathrm{cm}^{-1}\right)$ & Gaseous mixture & No. of narrow band \\
\hline $1950-2325$ & $\mathrm{H}_{2} \mathrm{O}-\mathrm{CO}_{2}-\mathrm{CO}$ & 16 \\
$2350-2425$ & $\mathrm{H}_{2} \mathrm{O}-\mathrm{CO}_{2}$ & 4 \\
$2450-3200$ & $\mathrm{H}_{2} \mathrm{O}$ & 31 \\
$3225-3775$ & $\mathrm{H}_{2} \mathrm{O}-\mathrm{CO}_{2}$ & 23 \\
$3800-4350$ & $\mathrm{H}_{2} \mathrm{O}-\mathrm{CO}$ & 23 \\
\hline
\end{tabular}

1). For both altitudes, the intensity leaving a line of sight is computed with the LBL, CK, CKFG, CK-SMG, and CKFG-SMG models in three spectral intervals given in Table 2. As Beier and Lindermeir [14] specified, these spectral intervals are frequently used for missile detection.

In Table 2, the computational time required for each model is evaluated. Because the time of computation depends on the computer and programming, the number of transmittivity $\tau_{i j}\left(n, N_{c}\right)$ (Eq. (5)) required in a spectral interval is chosen as an indicator for the computation time. In a spectral interval, such as [2000-2500 $\left.\mathrm{cm}^{-1}\right]$, the number of $\tau_{i j}\left(n, N_{c}\right)$ required in a narrow band depends on the number of overlapping gases. The spectral intervals where the gases overlap are given in Table 3. Furthermore, in order to find an equivalent indicator for the LBL method, the number of monochromatic transmittivity $\tau_{\nu}\left(n, N_{c}\right)$ needed to compute the narrow band intensities is also presented in Table 2 (the resolution of the LBL spectra is $5 \times 10^{-4} \mathrm{~cm}^{-1}$ ). Table 2 illustrates the time savings when the spectral narrow band models are used. Moreover, for the spectral intervals considered in this study, the SMG assumption reduces the computation time by at least half.

In the following, the accuracy of each narrow band model is investigated in two cases: the remote sensing of high temperature plume at sea level (Case 1, Table 1) and at high altitude (Case 2, Table 1). Considering three spectral intervals (Table 2), the accuracy of a narrow band model is evaluated with the $R$ ratio defined as the average difference of the intensity between the narrow band model and the reference model. Its expression is as follows:
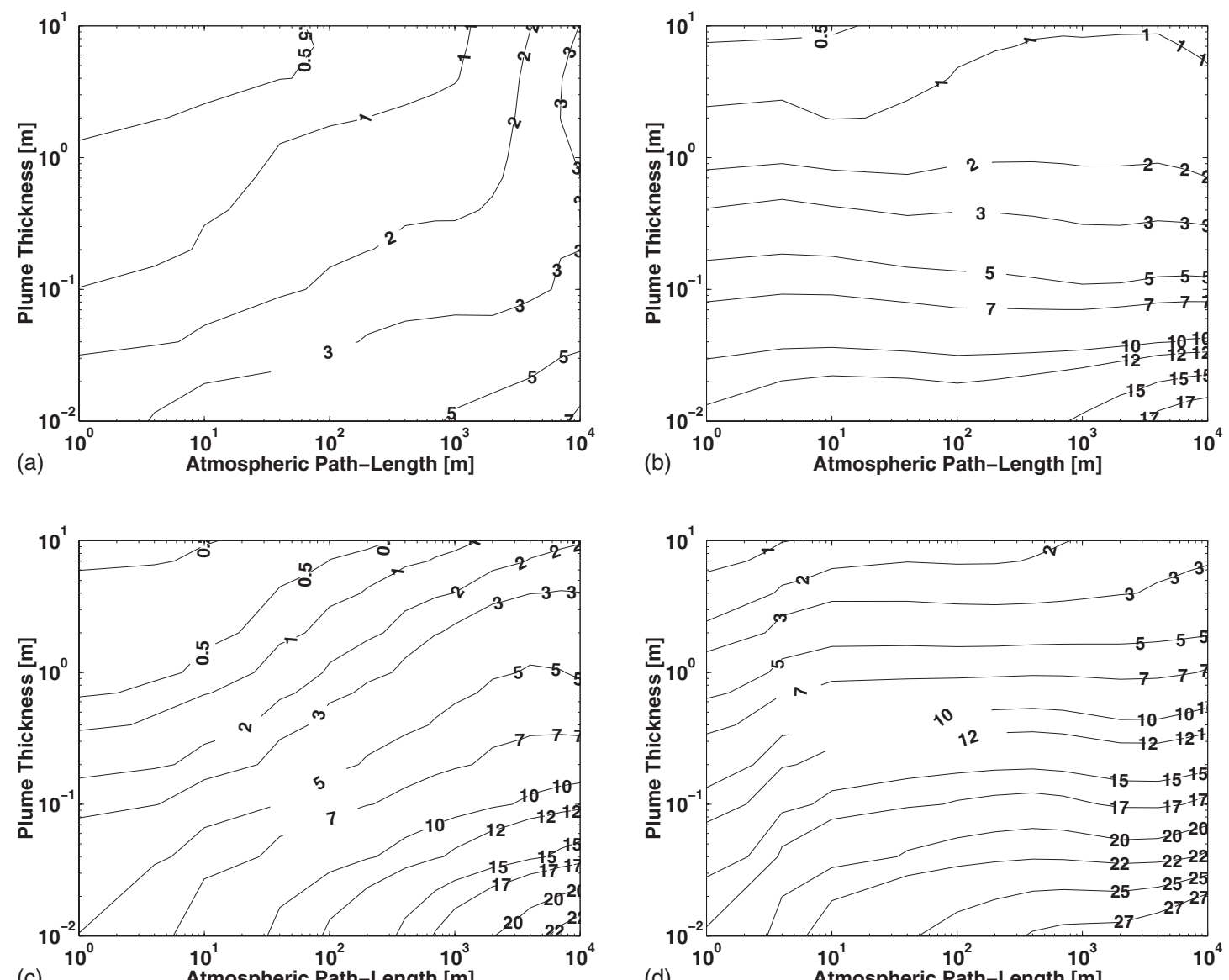

Fig. 2 Mappings of the $R$ ratio in the spectral interval $2000-2500 \mathrm{~cm}^{-1}$ versus the atmospheric path-length and the plume thickness (a) CKFG-SMG and CKFG in Case 1, (b) CKFG-SMG and CKFG in Case 2, (c) CK-SMG and CK in Case 1, and (d) CK-SMG and CK in Case 2 


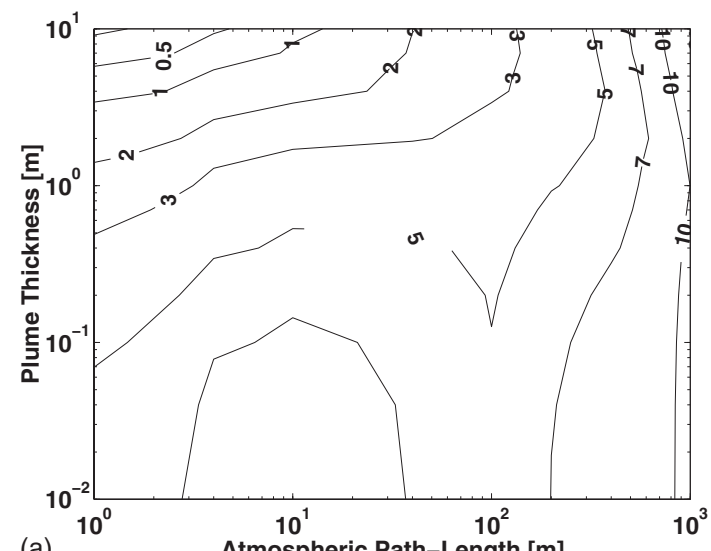

(a)

Atmospheric Path-Length [m]
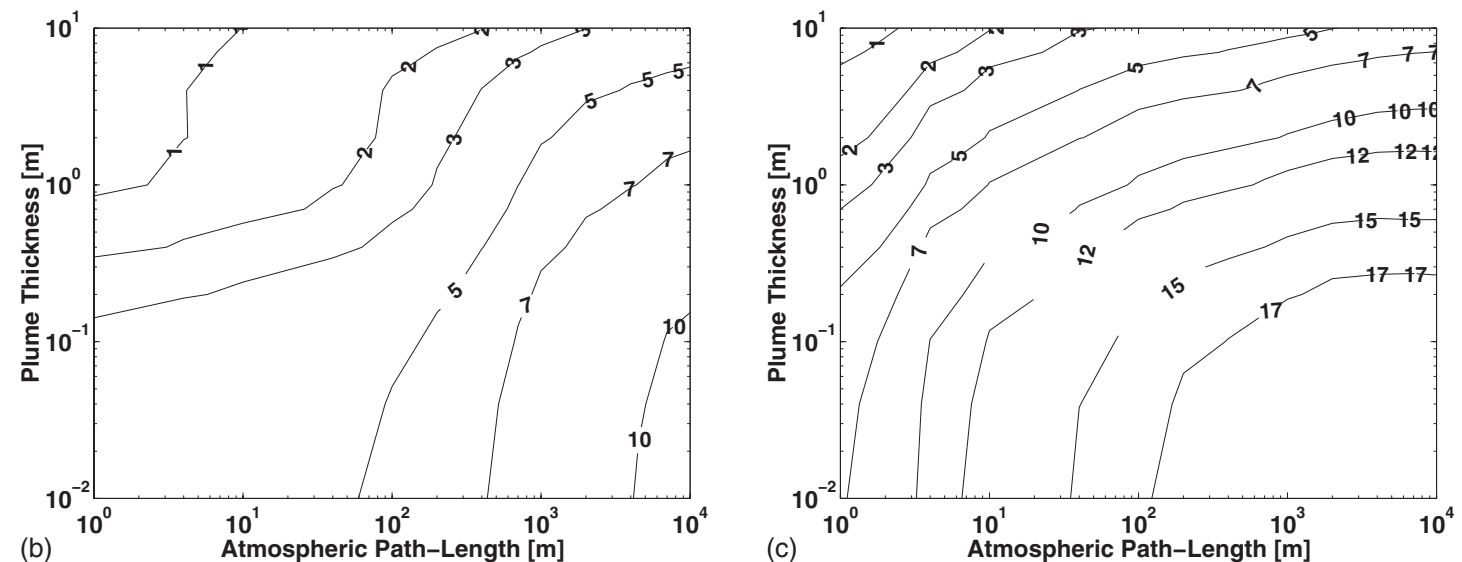

Fig. 3 Mappings of the $R$ ratio in the spectral interval $3450-3850 \mathrm{~cm}^{-1}$ versus the atmospheric path-length and the plume thickness for (a) CKFG-SMG and CKFG in Case 1, (b) CKFG in Case 2, and (c) CKFG-SMG in Case 2

$$
R=100\left(\sum_{k=1}^{N_{b}} \bar{I}_{\mathrm{LBL}, k}\right)^{-1} \sum_{k=1}^{N_{b}}\left|\bar{I}_{\mathrm{LBL}, k}-\bar{I}_{\mathrm{NB}, k}\right|
$$

where $N_{b}$ is the number of bands included in the spectral intervals (Table 2). $\bar{I}_{\mathrm{LBL}, k}$ and $\bar{I}_{\mathrm{NB}, k}$ are, respectively, the average intensity, in the $k$ th narrow band, obtained with the reference LBL approach and the intensity computed with a narrow band model (Eq. (3)) such as CK, CK-SMG, CKFG, or CKFG-SMG. The absolute value of the error due to the narrow band model is considered in Eq. (7) in order to avoid a balancing effect of the integrated error in the spectral interval. $R$ is not the relative error induced by a narrow band model on the integrated intensity in the spectral interval but is an indicator of the difference between a narrow band model and the LBL.

\section{Results and Discussion}

From Figs. 2-4, the mappings of the $R$ ratio are represented versus the atmospheric path length $\left(\ell_{a}\right)$ and the plume thickness $\left(\ell_{p}\right)$. The dependence of the $R$ ratio on the atmospheric path length and the plume thickness is investigated by covering a wide range of remote sensing configurations. The mappings in Fig. 2 show the spectral interval $2000-2500 \mathrm{~cm}^{-1}$, and the mappings in Figs. 3 and 4 show the spectral intervals $3450-3850 \mathrm{~cm}^{-1}$ and $3850-4150 \mathrm{~cm}^{-1}$, respectively.

The figures of the $R$ ratio highlight four sources of discrepancies between the narrow band models and the LBL. First, the increase in the plume thickness results in an enlargement of the

line wing contribution to the emitted radiation by the plume. The overlapping of several line wings create a continuum, which helps to decrease the overcorrelation effects between lines from different lower-state energies. Consequently, the errors of the narrow band models tend to be smaller when the plume thickness increases. The second source of discrepancies is illustrated by the higher value of $R$ for the low pressure case. At low pressure, the collision broadening of the lines is weak, and the optical thickness of the corresponding line wings is almost zero. For the spectra involved in Case 2, the lines are more spaced and the emitted radiation is concentrated at the center of the lines. The errors due to the correlation of lines from different lower-state energies are enhanced, and $R$-values are greater at high altitude than at sea level. The third source of discrepancies is the overestimate of the atmospheric absorption, due to the spectral correlations. In summary, long atmospheric path length and low pressure result in the increase in the $R$ ratio. In contrast, the increase in the plume thickness tends to reduce the $R$ ratio. If the effects of the atmospheric path length and the plume thickness are competitive, the mappings show curved isolines of $R$. When one of these effects prevails, the isolines of $R$ are either vertical if the effect of atmospheric path length is dominant or horizontal if the effect of the plume thickness is predominant. The fourth source of discrepancies affects only the models with the SMG assumption since it is related to the overcorrelation of lines belonging to different real gases.

In Fig. 2, each frame represents the results of two models: CKFG-SMG and CKFG, shown in Figs. 2(a) and 2(b), and CK 

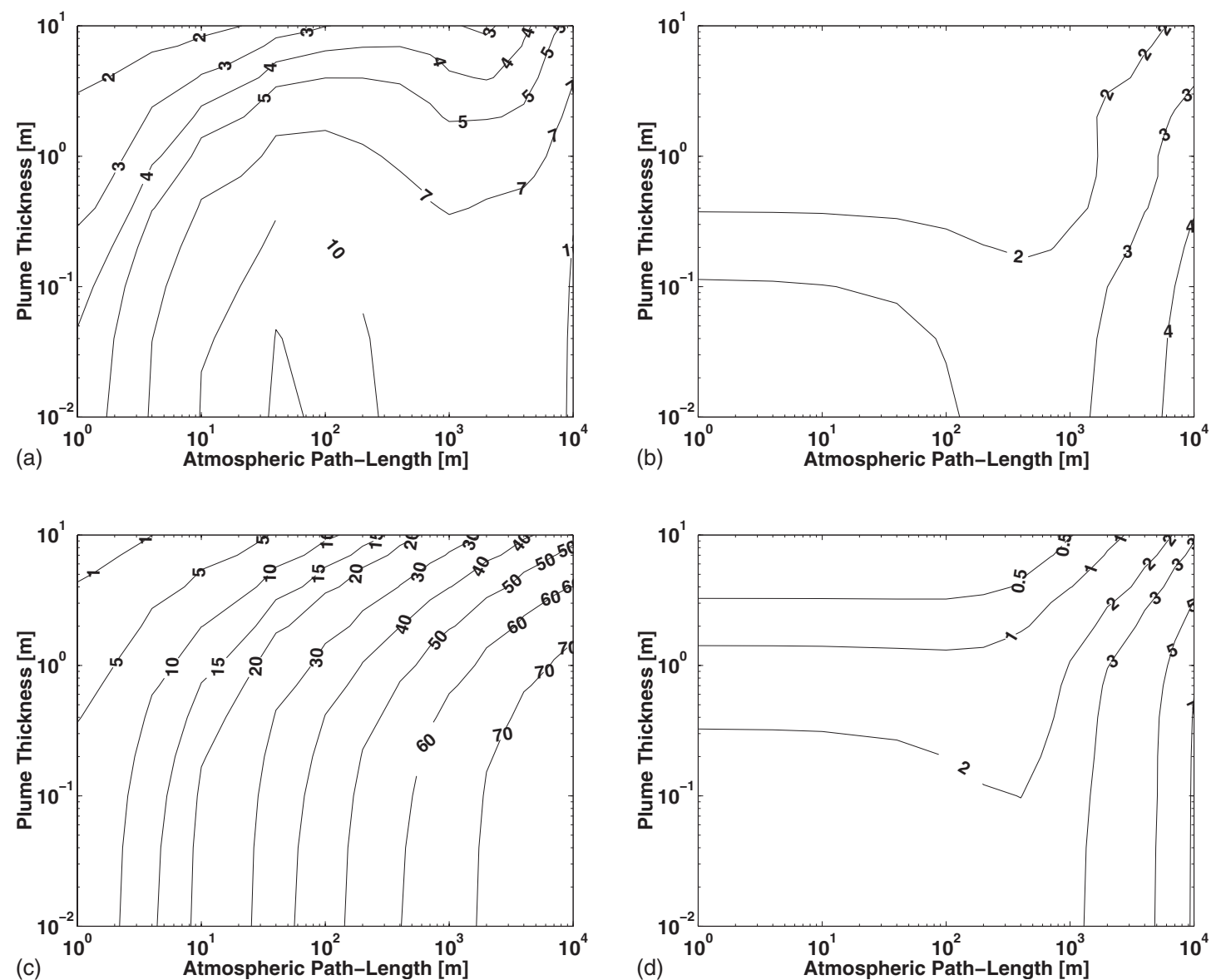

Fig. 4 Mappings of the $R$ ratio in the spectral interval $3850-4150 \mathrm{~cm}^{-1}$ versus the atmospheric path-length and the plume thickness for (a) CKFG-SMG and CKFG in Case 1, (b) CKFG-SMG and CKFG in Case 2, (c) CK-SMG and CK in Case 1, and (d) CK-SMG and CK in Case 2

and CK-SMG models, shown in Figs. 2(c) and 2(d). Indeed, in such cases, both models give similar results. There are two reasons for this, which are due to the specificity of the spectral distribution of the lines in this interval. First, the lines of $\mathrm{H}_{2} \mathrm{O}$ and $\mathrm{CO}_{2}$ do not overlap in the atmospheric spectrum (cold lines). Second, $\mathrm{H}_{2} \mathrm{O}$ cold lines only absorb the intensity emitted by the $\mathrm{H}_{2} \mathrm{O}$ lines of the high temperature spectrum. In the same manner, the $\mathrm{CO}_{2}$ cold lines absorb principally the intensity emitted by the $\mathrm{CO}_{2}$ lines. That is why the SMG assumption does not introduce a supplementary error and the two models give identical results. Moreover, the contribution of CO to the overall atmospheric absorption is negligible in view of its low concentration. At sea level, CKFG and CKFG-SMG reach a good accuracy since $R$ $\leqslant 7 \%$. At high altitude, both models give also good results $(R$ $\leqslant 5 \%$ ) if the plume thickness is greater than $0.1 \mathrm{~m}$. As the plume thickness increases, the $R$ ratio decreases. The comparison of the $R$ values involved in Figs. 2(a) and 2(b) shows the role of the pressure on $R$, which enhances the spectral overcorrelation effects. In the spectral interval $\left[2000-2500 \mathrm{~cm}^{-1}\right]$, the CK-SMG and CK models can be used $(R \leqslant 7 \%)$ if the plume thickness is greater than $1 \mathrm{~m}$.

For the remote-sensing application at sea level, Fig. 3(a) represents the mapping of the $R$ ratio obtained either with the CKFGSMG model or the CKFG model, in the spectral interval $3450-3850 \mathrm{~cm}^{-1}$. In this figure, the atmospheric path length is truncated to $1 \mathrm{~km}\left(10^{3} \mathrm{~m}\right)$; beyond this value, the average intensity in the spectral interval is not significant. Figure 3(a) shows that both models, considering FGs, lead to a difference compared to the reference (LBL) of 5-10\% when the atmospheric path increases. For the high altitude case, the mappings of $R$ for the CKFG and CKFG-SMG models are, respectively, presented in Figs. 3(b) and 3(c). In this spectral interval, $\mathrm{H}_{2} \mathrm{O}$ and $\mathrm{CO}_{2}$ lines overlap. Then, the SMG assumption introduces additional errors due to the change in mole fraction. It is for this reason that the CKFG model $(R<10 \%)$ has better accuracy than the CKFGSMG model $(R<17 \%)$. Although the SMG assumption introduces supplementary errors, both models reach values of the $R$ ratio greater than $5 \%$. The models do not give a sufficiently good accuracy when the long atmospheric path is considered. The results for the CK and CK-SMG models are not shown in this case because of their low accuracy. For this spectral interval, $3450-3850 \mathrm{~cm}^{-1}$, the LBL approach is recommended if a very high accuracy is necessary. If an $R$ ratio close to $10 \%$ is a tolerable accuracy, the CKFG-SMG model should be used for applications at sea level; at high altitude, the CKFG model is recommended.

Figures $4(a)-4(d)$ represent the mapping of the $R$ ratio obtained with the narrow band models in the spectral interval $3850-4150 \mathrm{~cm}^{-1}$. The results computed with the CKFG model are similar to those computed with the CKFG-SMG model. In the same manner, the results of the CK model are identical to those obtained with the CK-SMG model. Figure 4(a) shows that the $R$ ratio reaches values around $10 \%$ for the remote-sensing case at the sea level, whereas for the high altitude case (Fig. 4(b)), the $R$ ratio takes values lower than 5\%. At the sea level, the models using the FGs do not seem to be accurate enough. This is due to the optical thickness of $\mathrm{H}_{2} \mathrm{O}$, which is larger at sea level than at high altitude. 
In addition, when FGs are not used, e.g., with the CK and CKSMG models in Fig. 4(c), the $R$ ratio exceeds 50\%. Comparing Figs. $4(c)$ and $4(d)$, the same conclusions can be drawn. The influence of $\mathrm{H}_{2} \mathrm{O}$ concentration leads to a better accuracy of the CK and CK-SMG models at high altitude than at the sea level.

\section{Summary and Conclusion}

The present study evaluates the accuracy of the narrow band models in two specific applications: the remote sensing of a high temperature plume at sea level and at high altitude. In the spectral ranges studied, $2000-2500 \mathrm{~cm}^{-1}, \quad 3450-3850 \mathrm{~cm}^{-1}$, and $3850-4150 \mathrm{~cm}^{-1}$, the CKFG and the CKFG-SMG models are found to have identical accuracies in remote-sensing applications. However, an exception occurs for the high altitude case in the spectral interval $3450-3850 \mathrm{~cm}^{-1}$. At high altitude, the CKFG model gives an $R$ ratio lower than $10 \%$, which is better than the CKFG-SMG, which reaches 17\%. In this particular case, the SMG assumption provokes an additional difference. Overall, this study shows that the error induced by the SMG assumption is almost negligible. However, if the two models are compared in terms of computing time, the CKFG-SMG needs half of the computational time required by the CKFG model. In most cases, the CKFGSMG model is the most efficient narrow band model, among the ones studied in this paper, for the remote sensing of a high temperature plume.

\section{References}

[1] Rothman, L. S., Wattson, R. B., Gamache, R. R., Schroeder, and J., and McCann, A., 1995, "HITRAN HAWKS and HITEMP High-Temperature Molecular Database," Proc. SPIE, 2471, pp 105-111.

[2] Partridge, H., and Schwenke, D. W., 1997, "The Determination of an Accurate
Isotope Dependent Potential Energy Surface for Water From Extensive Ab Initio Calculations and Experimental Data," J. Chem. Phys., 106, pp. 46184639.

[3] Tashkun, S. A., Perevalov, V. I., Teffo, J.-L., Bykov, A. D., and Lavrentieva, N. N., 2003, "CDSD-1000, the High-Temperature Carbon Dioxide Spectroscopic Databank," J. Quant. Spectrosc. Radiat. Transf., 82, pp. 165-196.

[4] Bharadwaj, S. P., and Modest, M. F., 2007, "Medium Resolution Transmission Measurements of $\mathrm{CO}_{2}$ at High Temperature: An Update," J. Quant. Spectrosc. Radiat. Transf., 103, pp. 146-155.

[5] Taine, J., and Soufiani, A., 1999, "Gas IR Radiative Properties: From Spectroscopic Data to Approximate Models," Adv. Heat Transfer, 33, pp. 295-341.

[6] Lacis, A., Wang, W. C., and Hansen, J., 1979, "Correlated K-Distribution Method for Radiative Transfer in Climate Models: Application to Effect of Cirrus Clouds on Climate," NASA Conf. Publ., 2076, pp. 309-314.

[7] Ludwig. C. B., Malkmus, W. Reardon, J. E., and Thomson, J. A.L., 1973, "Handbook of Infrared Radiation From Combustion Gases," NASA SP-3080.

[8] Rivière, P., Soufiani, A., and Taine, J., 1992, "Correlated-K and Fictitious Gas Methods for $\mathrm{H}_{2} \mathrm{O}$ Near $2.7 \mu$ m," J. Quant. Spectrosc. Radiat. Transf., 48, pp. 187-203.

[9] Levi Di Leon, R., and Taine, J., 1986, "A Fictive Gas-Method for Accurate Computations of Low Resolution, IR Gas Transmissivities: Application to the $4.3 \mu \mathrm{m} \mathrm{CO}{ }_{2}$ Band," Rev. Phys. Appl., 21, pp. 825-831.

[10] Caliot, C., Le Maoult, Y., El Hafi, M., and Flamant, G., 2006, "Remote Sensing of High Temperature $\mathrm{H}_{2} \mathrm{O}-\mathrm{CO}_{2}-\mathrm{CO}$ Mixture With a Correlated K-Distribution Fictitious Gas Method and the Single Mixture Gas Assumption,” J. Quant. Spectrosc. Radiat. Transf., 102, pp. 304-315.

[11] Fu, Q., and Liou, K. N., 1992, "On the Correlated K-Distribution Method for Radiative Transfer in Nonhomogenous Atmospheres," J. Atmos. Sci., 49, pp. 2139-2156.

[12] Caliot, C., 2006, "Modélisation et Simulation de l'Emission Energétique et Spectrale d'un Jet Réactif Composé de Gaz et de Particules à Haute Température Issus de la Combustion d'un Objet Pyrotechnique." Ph.D. thesis, Institut National Polytechnique de Toulouse, Toulouse.

[13] Mc Clatchey, R. A., Fenn, R. W., Selby, J. E.A., Voltz, F. E., and Garing, J. S., 1971, "Optical Properties of the Atmosphere," Air Force Cambridge Res Lab, Tech Report No. AFCRL-71-0279.

[14] Beier, K., and Lindermeir, E., 2007, "Comparison of Line-by-Line and Molecular Band IR Modeling of High Altitude Missile Plume," J. Quant. Spectrosc. Radiat. Transf., 105, pp. 111-127. 